\title{
Rate of ectopic pregnancy in Madinah Maternity and Children Hospital, Madinah, Saudi Arabia
}

\author{
Dr Mohammad Othman ${ }^{1}$, Dr Mohammed Al-Alwan ${ }^{2}$, Dr Jehan Al-Hazmi ${ }^{3}$ \\ ${ }^{I}$ Consultant and Assistant Professor, Department of Obstetrics and Gynecology, Faculty of Medicine, Al- \\ Baha University, \\ ${ }^{2}$ Senior Resident, Department of Obstetrics and Gynecology, Madinah Maternity and Children Hospital) \\ (3Consultant, Department of Obstetrics and Gynecology, Madinah Maternity and Children Hospital)
}

\begin{abstract}
Ectopic pregnancyhas been reported to be increasing in many countries in recent years. Mortality rate for ectopic pregnancy are 32 per 100,000 deliveries. Complications of ectopic pregnancy can be secondary to misdiagnosis, late diagnosis, or treatment approach.Thisstudy aimed to evaluate the rate and the management of ectopic pregnancy in Madinah Maternity and Children Hospital, Madinah, Saudi Arabia. This is a retrospective study, carried out over all the year of 2016.66 patients were confirmed cases of ectopic.Most of the patients were university educated multipara Saudi women between the age 28 and 38 years. Use of assisted techniques of reproduction seems to be the highest cause for ectopic pregnancy. Ovulation induction techniques are the highest among this group since 28 of those 30 patients (93.3\%) where using ovulation induction treatments to get pregnant.The rate of ectopic pregnancy in MMCH was 3.8\% of all the early pregnancy bleeding cases in 2016.More than 92\% of the treated surgically patients were using laparotomy. There is a high need for further research to follow the rate of ectopic pregnancy not only in MMCH but also for the whole Saudi Arabia, with study of the causes and management.Induction of ovulation should be evaluated as a strong cause of ectopic pregnancy. Lastly, there is a need for training doctors on using laparoscopy.
\end{abstract}

Keywords: Ectopic pregnancy, Ovulation induction, Salpingitis, Pelvic inflammation, Laparotomy, Bleeding.

\section{Introduction}

Blastocyst normally implants in the endometrial lining of the uterine cavity. Implantation anywhere else is considered an ectopic pregnancy. $2 \%$ of all first trimester pregnancies are ectopic pregnancies. The incidence of ectopic pregnancy has been reported to be increasing in many countries in recent years because of a number of factors. These factors include increased rate of sexually transmitted infections that damage the fallopian tubes, the use of antibiotic treatments for pelvic inflammatory disease, more accurate methods for early detection of ectopic pregnancy, increased use of assisted reproductive technologies and increased rates of tubal sterilization [1]. Prior tubal damage confers the highest risk for ectopic pregnancy [2,3].

Estimated mortality rate for ectopic pregnancy are 32 per 100,000 deliveries compared with maternal death rate of 7 per 100,000 live births [4]. Twin tubal pregnancy with both embryos in the same tube as well as with one in each tube has been reported $[5,6]$.

When an ectopic pregnancy in the fallopian tube is treated conservatively, there is a roughly 10 fold increase in ectopic pregnancy in future pregnancy $[7,8]$. Post conservative management of ectopic pregnancy adhesions develops in the pelvic area and in turn, presence of pelvic adhesions increase the rate of ectopic pregnancy $[9,10]$.

Complications of ectopic pregnancy can be secondary to misdiagnosis, late diagnosis, or treatment approach. Failure to make the prompt and correct diagnosis of ectopic pregnancy can result in tubal or uterine rupture (depending on the location of the pregnancy), which in turn can lead to massive hemorrhage, shock, disseminated intravascular coagulopathy [11], and death. Ectopic pregnancy is the leading cause of maternal death in the first trimester, accounting for 9-13\% of all pregnancy-related deaths. In the United States, an estimated 30-40 woman dies each year from ectopic pregnancy. Any time a surgical approach is chosen as the treatment of choice, consider the complications attributable to the surgery, whether it is laparotomy or laparoscopy [12].

The principle management in case of ectopic pregnancy has become a conservative approach that attempts to save the tube, rather than salpingectomy. However, it is important to remember that hemorrhage from ectopic pregnancy is still the leading cause of pregnancy related maternal death in the first trimester and accounts for 4 to 10 percent of all pregnancy related deaths, despite improved diagnostic methods leading to earlier detection and treatment [13,14]. Despite the risk of persistent ectopic pregnancy, some studies have shown salpingestomy to improve reproductive outcome in patients with contra-lateral tubal damage. Yao and Tulandi concluded from a literature review that laparoscopic salpingestomy had a reproductive performance that was equal to or slightly better than salpingectomy; however, slightly higher recurrent ectopic pregnancy rates 
were noted in the salpingestomy group [15]. However, if the treating surgeon has neither the laparoscopic skill nor the instrumentation necessary to atraumatically remove the trophoblastic tissue via linear salpingestomy, then salpingectomy by laparoscopy or laparotomy is not the wrong surgical choice [16].

The present study aimed to evaluate the rate and the management of ectopic pregnancy in Madinah Maternity and Children Hospital, Madinah, Saudi Arabia.

\section{Methodology}

This is a retrospective study, which was carried out in Madinah Maternity and Children Hospital $(\mathrm{MMCH})$, Madinah, Saudi Arabia. Ectopic pregnancy patient records was identified and data was extracted from ectopic pregnancy patient's records in the hospital from first January 2016 to end of December 2016. Due to the retrospective nature of the study, informed consent was not necessary but patient records were deidentified prior to analysis. Study was conducted between $18^{\text {th }}$ and end of March 2017.

Madinah MCH (MMCH) is a tertiary hospital where medical care is given free of charge. MCH cover the whole region of Madinah which is $151,990 \mathrm{~km} 2(58,680 \mathrm{mi2})$, with a total multi ethnic population of 1,977,933. $\mathrm{MCH}$ lies in Madinah which is the capital of the region and the second holiest city in Islam [17]. MCH average number of deliveries is 15,000 per year, and caesarian section rate is $21 \%$.Ectopic pregnancy was defined as any pregnancy outside the uterus. Diagnosis is confirmed by both abdominal or vaginal ultrasound (US) and $\beta$ human chorionic gonadotropin ( $\beta$-hCG) level in blood on admission and after 48 hours.

We designed a form to extract data from patient's records. Outcomes include demographic characteristics of the participants (nationality, age, parity, gestational age at time of diagnosis, history of assisted pregnancy and history of previous abdominal operations), method of management, and hospital course. Simple descriptive analysis used.

\section{Results}

During the period of the study, there was 1984 patient admitted as bleeding in early pregnancy (Table 1).

\begin{tabular}{|l|l|l|l|}
\hline $\begin{array}{l}\text { Patients admitted as } \\
\text { bleeding in early } \\
\text { pregnancy } \\
\mathrm{N}(\%)\end{array}$ & $\begin{array}{l}\text { Confirmed patients of } \\
\text { different types of abortion } \\
\mathrm{N}(\%)\end{array}$ & $\begin{array}{l}\text { Confirmed patients of } \\
\text { molar pregnancy } \\
\mathrm{N}(\%)\end{array}$ & $\begin{array}{l}\text { Confirmed patients of } \\
\text { ectopic pregnancy } \\
\mathrm{N}(\%)\end{array}$ \\
\hline $1744(100 \%)$ & $1658(95.07 \%)$ & $20(1.15 \%)$ & $66(3.78 \%)$ \\
\hline
\end{tabular}

Table 1: patient admitted as bleeding in early pregnancy in 2016

There were 75 patients admitted as suspected ectopic pregnancy. 66 patients only were confirmed cases of ectopic, while, the other 9 patient were diagnosed as threatened abortion. Demographic characteristics of ectopic pregnancy patients can be seen in (Table 2). Most of the patients were university educated multipara Saudi women between the age 28 and 38 years.

\begin{tabular}{|c|c|c|}
\hline \multicolumn{2}{|l|}{ Parameters } & Ectopic pregnancy patients $\mathrm{N}(\%)$ \\
\hline \multirow{3}{*}{ Age } & 18-28 Y's & $3(4.55 \%)$ \\
\hline & $28<-38$ Y's & $49(74.24 \%)$ \\
\hline & $38<-45$ Y's & $14(21.21 \%)$ \\
\hline \multirow[t]{2}{*}{ Nationality } & Saudi & $62(93.94 \%)$ \\
\hline & Non-Saudi & $4(6.06 \%)$ \\
\hline \multirow{3}{*}{ Education } & High school & $15(22.72 \%)$ \\
\hline & University & $48(72.73 \%)$ \\
\hline & Higher education & $3(4.55 \%)$ \\
\hline \multirow{3}{*}{ Parity } & $\mathrm{PG}$ & $3(4.55 \%)$ \\
\hline & $\mathrm{P} 1-\mathrm{P} 4$ & $56(84.85 \%)$ \\
\hline & $\mathrm{P} 5 \leq$ & $7(10.6 \%)$ \\
\hline \multirow{2}{*}{$\begin{array}{l}\text { History of previous ectopic } \\
\text { pregnancy }\end{array}$} & Yes & $4(6.06 \%)$ \\
\hline & No & $62(93.94 \%)$ \\
\hline \multirow{2}{*}{$\begin{array}{l}\text { History of previous } \\
\text { abdominal surgery }\end{array}$} & Yes & $23(34.85 \%)$ \\
\hline & No & $43(65.15 \%)$ \\
\hline
\end{tabular}

Table 2: Demographic characteristics

We analysed each patient file to study the possible causes, management done and hospital course (Table 3). Use of assisted techniques of reproduction seems to be the highest cause for ectopic pregnancy. Ovulation induction techniques are the highest among this group since 28 of those 30 patients $(93.3 \%$ ) where using ovulation induction treatments to get pregnant. All ovulation induction patients were booked for these treatments in private hospitals and clinics. The second highest cause was the presence of previous abdominal and tubal operations. There was 4 patients had history of previous ectopic pregnancy all treated surgically. Two 
of them had salpingestomy of the same tube were the ectopic pregnancy occur in the current ectopic, and 2 had salpingectomy before. Presence of pelvic inflammatory disease represented more than $10 \%$ of the causes of ectopic pregnancy. The last two patients we could not find any risk factors. 61 patients were treated surgically, among them 12 patients (19.67\%) only had salpingestomy, while the other 49 patients (80.33\%) had salpingectomy. All patients had laparotomy. Further to that, one of the medically treated ectopic pregnancy patients, two days post treatment developed severe abdominal pain and started to develop hypovolemic shock, she was taken immediately for laparotomy were left salpingectomy was done.

\begin{tabular}{|l|l|l|}
\hline Parameters & $\begin{array}{l}\text { Ectopic pregnancy patients } \\
\mathrm{N}(\%)\end{array}$ \\
\hline \multirow{4}{*}{ Causes } & Previous abdominal surgery & $27(40.92 \%)$ \\
\cline { 2 - 3 } & $\begin{array}{l}\text { Known to have Pelvic } \\
\text { Inflammatory Disease }\end{array}$ & $7(10.6 \%)$ \\
\cline { 2 - 3 } & $\begin{array}{l}\text { Use of assisted reproduction } \\
\text { techniques in current pregnancy }\end{array}$ & $30(45.48 \%)$ \\
\cline { 2 - 3 } & Unknown & $2(3.0 \%)$ \\
\hline \multirow{3}{*}{ Management } & Medical & $5(7.58 \%)$ \\
\cline { 2 - 3 } & Surgical & $61(92.42 \%)$ \\
\cline { 2 - 3 } & Referred to higher centre & 0 \\
\hline Hospital course & Further intervention & $65(1.52 \%)$ \\
\cline { 2 - 3 } & Good & $c 08.48 \%)$ \\
\hline
\end{tabular}

Table 3: Causes, management and complications.

Among those ectopic pregnancy patients 19 patients $(28.79 \%)$ are newly pregnant after that ectopic episode and are booked in MMCH. Also, 5 patients (7.58\%) of ectopic pregnancy patients, admitted as incomplete abortion and were managed and discharged in good condition.

\section{Discussion}

During 2016 there was 15096 deliveries, 10234 vaginal deliveries and 4790 LSCS deliveries. There was 1862 patients came to emergency room and clinic complaining of vaginal bleeding. Among them 1744 patients were diagnosed as bleeding in early pregnancy.

In the United States, ectopic pregnancy is estimated to occur in 1-2\% of all pregnancies and accounts for 3-4\% of all pregnancy-related deaths [18]. It is the leading cause of pregnancy-related mortality during the first trimester. In a review of deaths from ectopic pregnancy in Michigan, $44 \%$ of the women who died were either found dead at home or were dead on arrival at the emergency department [19].

Complications of ectopic pregnancy can be secondary to misdiagnosis, late diagnosis, or treatment approach. Failure to make the prompt and correct diagnosis of ectopic pregnancy can result in tubal or uterine rupture (depending on the location of the pregnancy), which in turn can lead to massive hemorrhage, shock,disseminated intravascular coagulopathy [11], and death. Ectopic pregnancy is the leading cause of maternal death in the first trimester, accounting for $9-13 \%$ of all pregnancy-related deaths. In the United States, an estimated 30-40 woman dies each year from ectopic pregnancy. Any time a surgical approach is chosen as the treatment of choice, consider the complications attributable to the surgery, whether it is laparotomy or laparoscopy [12].

Parker and Bistis concluded that when the contra-lateral fallopian tube is normal, the subsequent fertility rate is independent of the type of surgery [20]. Similarly, a prospective study of 88 patients by Ory et al indicated that the surgical method had no effect on subsequent fertility in women with an intact contra-lateral tube [21]. Several other studies reported that the status of the contra-lateral tube, the presence of adhesions, and the presence of other risk factors, such as endometriosis, have a more significant impact on future fertility than does the choice of surgical procedure [16]. According to Ruling, salpingectomy should be the treatment of choice in women with intact contra-lateral tubes, because conservative treatment provides no additional benefit and incurs the additional costs and morbidity associated with persistent ectopic pregnancy and recurrent ectopic pregnancy in the already damaged tube [22]. Future fertility rates have been found to be similar in patients who are treated surgically by laparoscopy or laparotomy. Salpingectomy by laparotomy carries a subsequent intrauterine pregnancy rate of $25-70 \%$, compared with laparoscopic salpingectomy rates of $50-60 \%$. Very similar rates exist for laparoscopic salpingestomy versus laparotomy. The rate of persistent ectopic pregnancy between the 2 groups is also similar, ranging from 5-20\%. A slightly higher recurrent ectopic pregnancy rate exists in patients treated by laparotomy (7-28\%), regardless of conservative or radical approach, when compared with laparoscopy $(6-16 \%)$. This surprising finding is believed to be secondary to increased adhesion formation in the group treated by laparotomy [16].

Clausen results from the retrospective non-comparing materials revealed that there was no significant difference in intrauterine pregnancy rates, i.e. $46 \%$ following salpingestomy and $44 \%$ after salpingectomy. The 
repeat ectopic pregnancy rate was $10 \%$ following salpingestomy and $15 \%$ after salpingectomy [18]. The cumulative intrauterine pregnancy rate was significantly higher after salpingestomy (88\%) than after salpingectomy $(66 \%)$ after correction for confounding factors. No difference was found in the recurrence rate of ectopic pregnancy between the treatments (16\% vs 17\%). In patients with contra-lateral tubal pathology, the chance of pregnancy was poor (hazard ratio 0.463) and the risk of recurrence was high (hazard ratio 2.25), assessed with Cox regression. The rate of persistent ectopic pregnancy was $8 \%$ [19].

\section{Conclusions and recommendations}

The rate of ectopic pregnancy in MMCH was 3.8\% of all the early pregnancy bleeding cases in 2016. cause for these ectopic pregnancies was induction of ovulation followed by presence of previous abdominal and tubal surgery. More than $92 \%$ of the treated surgically patients were using laparotomy.

There is a high need for further research to follow the rate of ectopic pregnancy not only in MMCH but also for the whole Saudi Arabia, with study of the causes and management.

Induction of ovulation should be evaluated as a strong cause of ectopic pregnancy. This should be studied by the Ministry of Health in Saudi Arabia as some patients are using induction of ovulation medications to get pregnant fast without investigating the cause of pregnancy delay. Further to that some doctors are prescribing these medication to increase the chance of multiple pregnancy as requested by patients.

Lastly, there is a need for training doctors on using laparoscopy. This should be free or at least on symbolic fees to have good expert obstetricians on laparoscopy.

\section{References}

[1]. Andrews, J. and S. Farrell, Spontaneous bilateral tubal pregnancies: a case report. Journal of Obstetrics and Gynaecology Canada, 2008. 30(1): p. 51-4.

[2]. Ankum, W., B. Mol, F.V.d. Veen, and P. Bossuyt, Risk factors for ectropic pregnancy: A meta-analysis. Fertillity and Strelity, 1996. 65: p. 1093-9.

[3]. Barnhart, K., M. Sammel, C. Gracia, J. Chittams, A. Hummel, and A. Shaunik, Risk factors for ectopic pregnancy in women with symptomatic first-trimester pregnancies. fertillity and Strelity, 2006. 86: p. 36-43.

[4]. Grimes, D., Estimation of pregnancy-related morality risk by pregnancy outcome, United States, 1991 to 1999 . Am J Obstet Gynecol, 2006. 194(1): p. 92-94.

[5]. Berkes, E., G. Szendei, L. Csabay, Z. Sipos, J. Joo, and J. Rigo, Unilateral triplet ectopic pregnancy after in vitro fertilization and embryo transfer. Fertillity and Strelity, 2008. 90(5): p. 2003.e17.

[6]. Rolle, C., C. Wai, and B. Hoffman, Unilateral twin ectopic pregnancy in a patient with multiple sexually transmitted infections. Infectious Diseases in Obstetrics and Gynecology, 2004. 1: p. 1-3.

[7]. Daiter, E. Ectopic Precnancy: Incidence Rates \& Rick Factors Infertility and Reproductive Endocrinology Free Online Guides, 2012.

[8]. Rana, P., I. Kazmi, R. Singh, M. Afzal, F. Al-Abbasi, A. Aseeri, R. Singh, R. Khan, and F. Anwar, Ectopic pregnancy: a review. Archives of Gynecology and Obstetrics, 2013. 78(3): p. 1-13.

[9]. Abusheikha, N., O. Salha, and P. Brinsden, Extra-uterine pregnancy following assisted conception treatment. Human Reproduction Update, 2006. 6(1): p. 80-92.

[10]. Hamura, N., J. Bolnga, and H.A. R Wangnapi R, Rogerson SJ, Unger HW, The impact of tubal ectopic pregnancy in Papua New Guinea--a retrospective case review. BMC Pregnancy and Childbirth, 2013. 13(86): p. 1-8.

[11]. PracticeCommitteeoftheAmericanSocietyforReproductiveMedicine, Medical treatment of ectopic pregnancy. Fertillity and Strelity, 2006. 86(5): p. S96-S102.

[12]. Danilatos, G. Ectopic pregnancy. http://danilatos.gr/?p=77, 2013.

[13]. (CDC), Ectopic pregnancy--United States, 1990-1992. 1995, MMWR Morbidity and Mortality Weekly Report. p. 46.

[14]. Fylstra, D., Tubal pregnancy: a review of current diagnosis and treatment. Obstetrical and Gynecology Survey, 1998. 53(5): p. 320.

[15]. Yao, M. and T. Tulandi., Current status of surgical and nonsurgical management of ectopic pregnancy. Fertillity and Strelity, 1997. 67(3): p. 421-33.

[16]. Sepilian, V. and E. Wood Ectopic Pregnancy. http://emedicine.medscape.com/article/2041923-overview\#showall, 2013.

[17]. Information., C.D.O.S., Statistical Yearbook. Population. Vol. 47. 2011: Information.

[18]. MMWR, Ectopic pregnancy mortality - Florida, 2009-2010. Morbedity and Mortality Weekly Report, 2012. 61(6): p. 106-9.

[19]. Anderson, F., J. Hogan, and R. Ansbacher, Sudden death: ectopic pregnancy mortality. Obstetrics and Gynecology 2004. 103(6): p. 1218-23.

[20]. Rulin, M., Is salpingostomy the surgical treatment of choice for unruptured tubal pregnancy? Obstetrics and gynecology, 1995. 86(6): p. 1010-3.

[21]. Clausen, I. and Jan;75(1):8-12, Conservative versus radical surgery for tubal pregnancy. A review. Acta Obstetrical and Gynecological Scandnavia 1996. 75(1): p. 8-12.

[22]. Bangsgaard, N., C. Lund, B. Ottesen, and L. Nilas, Improved fertility following conservative surgical treatment of ectopic pregnancy. British Journal of Obsterical and Gyneacology, 2003. 110: p. 765-70. 